\title{
Being an exchange student in the USA: How does it affect a student's oral English skills? A case study.
}

Sigrunn Askland ${ }^{\mathrm{a}}$

a Dahlske Upper Secondary School, Grimstad

\begin{abstract}
It is uncontroversial to assume that learners of foreign languages who spend extended periods of time in an environment of native speakers will improve greatly with regard to oral skills. However, according to modern theories of Second Language Acquisition (SLA), it is also assumed that some features of a language are more difficult to acquire than others. This article explores how the oral English skills of a Norwegian teenager have developed in the course of one year as an exchange student in the USA. Fluency along with grammatical and phonological features have been examined before and after the student's stay abroad, and accuracy rates have been discussed and compared, also taking into account relevant theories of SLA. Finally, some didactic implications are addressed as to what aspects of English should be taught at what stage in a student's education.
\end{abstract}

\section{Introduction}

After having taught English and other foreign languages in Norwegian schools for almost two decades and also having studied Second Language Acquisition at the University of Agder, I have become very interested in the language acquisition process itself, and in particular what young learners of English need in order to improve their language skills. I am currently working as an English teacher at an upper secondary school in Norway, which means that I teach 100-150 students of foreign languages (English and Spanish) every year, including the first year course of general studies (studiespesialiserende vg 1) and the second year course 
(International English). Some of the first year students choose to go abroad for one year, and most of them go to the USA. Upon returning to Norway most of these tell me that the year has been educational, fun and rewarding, and that they feel that they notice considerable improvement of their English skills. Consequently, I was curious to find out how a year in an English-speaking environment might improve the speaking English skills of an average ${ }^{1} 17-$ year old Norwegian student. One female student agreed to let me interview her before and after her year in the USA, with the aim to assess her oral progress in English in the course of the year.

\section{Discussion of Theory}

This section includes theories that seem fruitful in order to describe and analyze the results of the interviews, as the aim of the theories is to explain why and how learner language develops the way it does, and why certain features of a language seem more difficult to acquire and improve than others.

Researchers have claimed that there is a critical period for language acquisition i.e. that after a certain age it is difficult to acquire oral language skills that equal those of a native speaker. This idea, called "The critical period hypothesis" (Lenneberg 1967), implies that the optimal age period for language acquisition is between the ages of two and puberty, and claims that humans are genetically programmed to acquire certain skills at a certain age. After this period, the theory states, it is increasingly difficult to learn to speak a language without revealing a foreign accent. According to Ortega (2009: 13) there is strong evidence for this hypothesis. However, some examples of successful late L2 learners do exist, correlating with high motivation and quality of instruction (Ortega 2009: 14-16).

It is generally assumed that there are some aspects of the English language - as the case may be for other languages - which are more difficult to acquire and improve than others once a student is past a certain age, in particular phonology, morphology and syntax ${ }^{2}$. As for phonology, this is often regarded as an area of language acquisition that is particularly strongly related to the critical period. Research generally supports this hypothesis, although exceptions exist also in this area. Again, the successful learners have been reported to have high levels of motivation and a concern to sound native-like (Ortega 2009: 23). With regard to morphology and syntax there is also evidence to suggest that learners who begin acquiring an

\footnotetext{
${ }^{1}$ I have chosen to define an average student as someone who receives the grades 3 and 4 in the Norwegian school system. ( 1 is fail, 6 is the best grade).

${ }^{2}$ See e.g. Ortega (2009) ch. 2, Singleton (1989), McLaughlin (1984).
} 
L2 at an early age are more likely to succeed than late starters. Interestingly, according to some findings, the learning of semantic features is different from the acquisition of other language features, and free from critical period constraints (Ortega 2009: 21), which may imply that it is easier for language learners at all levels to improve their vocabulary than other language features. However, there are several factors that contribute to a learner's ultimate attainment in a foreign or second language, such as quality of instruction, cognitive factors, the learner's first language ${ }^{3}$ and exposure to the language.

Finally, I will conclude this section by referring to fossilization, a term coined by Larry Selinker (1972). This term implies that there are certain features in a learner's language that may stop developing, despite exposure to the target language. Learners may achieve high levels of competence in the target language and still show signs of fossilization in terms of morphemes such as third person singular $-\mathrm{s}^{4}$. The reason may be that this language feature is semantically redundant and the learner therefore needs form-focused instruction to notice and acquire the correct form ${ }^{5}$. Furthermore, the affective filter hypothesis, introduced by Krashen $(1982)^{6}$, claims that factors such as motivation, self-confidence and anxiety greatly influence the language learning process and helps to explain why some learners are successful and others are not, despite continued exposure to the target language.

\section{Research questions}

Based on the theories put forward in the previous section, one would expect the student to improve more in some areas than others. The research questions thus investigate (a) whether the student improves significantly with regard to vocabulary and hence fluency, and (b) whether s/he experiences less improvement in phonology and morphology, possibly to the extent of fossilization.

\section{Method and research design}

As mentioned initially I was lucky to get the permission to interview a 17-year old girl before and after her high school year in the USA. I became acquainted with this student in

\footnotetext{
${ }^{3}$ For a discussion of L1 influence in SLA see Ortega (2009) ch. 4, Ortega (2009) ch. 3, Ringbom \& Jarvis (2011).

${ }^{4}$ See Ortega (2009) ch. 6 for examples of fossilization.

${ }^{5}$ Lightbown \& Spada p. 178

${ }^{6}$ The concept of an Affective Filter was proposed by Dulay and Burt (1977).
} 
connection with another research project that I carried out about the role of feedback in SLA (second language acquisition) ${ }^{7}$.

The first interview was conducted in mid-June, a few weeks before the student was to leave for the USA. The second interview took place in mid-June one year later, just a few days after her return to Norway. The interviews lasted for about half an hour each and were tape recorded. Only the student and the interviewer were present in the room during both interviews, and the student was aware of the purpose of the interviews. However, the questions were not presented to her prior to the interviews, and she was not asked to prepare anything. Neither the student nor the interviewer was pressed for time. Some questions were prepared in advance, e.g. about the student's expectations for the year in the USA, what she thought she would miss during her period abroad, etc., but questions were also created spontaneously during the interview, based on what the student responded or brought up about the different subjects that were introduced to her. The primary goal was to assess the student's ability to talk freely and fluently in English about several unplanned, everyday topics.

To facilitate the assessment of the student's English skills, I needed to determine which language variables to include in the analysis of the results. To assess speech is a very complicated task, and it was difficult to find a useful model of doing so for the purpose of this article $^{8}$. There are several areas of speech suitable for examination, such as phonological, grammatical and discourse features ${ }^{9}$. As one of my primary goals was to assess fluency, I decided to include lack of fluency as one variable. However, fluency is a highly problematic term to define ${ }^{10}$, and for the purpose of this article, lack of fluency implies that the student is unable to continue the sentence because she lacks the appropriate word and is unable to find a replacement word or phrase in English, or that she simply replaces an English word with a Norwegian word.

In addition, I chose to include the following elements of grammar and phonology: lack of subject-verb agreement and confusion of the sounds $/ \mathrm{t} / \mathrm{vs}$. $/ \theta /$ and $/ \mathrm{v} / \mathrm{vs}$. /w/ in words such as think and visit respectively. Standard Norwegian does not mark subject-verb agreement, and the sounds $/ \theta /$ and $/ \mathrm{w} /$ do not exist in the Norwegian language. Consequently, these are elements of English that Norwegian learners tend to find difficult to master correctly ${ }^{11}$.

\footnotetext{
${ }^{7}$ Askland (2010): The Role of Instruction and Feedback in Second language Acquisition.

${ }^{8}$ For a discussion of methods to assess speaking, see e.g. Luoma (2004).

${ }^{9}$ See Bygate (2011) for further discussion of linguistic features.

${ }^{10}$ See e.g. Luoma (2004).

${ }^{11}$ As for subject -verb agreement see e.g. Krashen (1982), Ellis (2009), Askland (2010).
} 
Additional variables could have been included in a more extensive study, e.g. grammatical features such as the student's use of verb tenses, determiners, prepositions, word order and phonological features that do not exist in most variants of Norwegian, such as e.g./ $\mathrm{t} / \mathrm{as}$ in church. The student's development with regard to vocabulary and use of "smallwords" also interesting areas for research.

\section{Analysis of the results}

\section{Table 1.0 Variables}

\begin{tabular}{|c|c|c|c|c|}
\hline & $\begin{array}{l}1 \text { Lack of } \\
\text { fluency }\end{array}$ & $\begin{array}{l}2 \text { Subject - } \\
\text { verb } \\
\text { agreement, } \\
\text { third person-s, } \\
\text { present tense }\end{array}$ & $\begin{array}{l}3 / \mathrm{t} / \mathrm{vs} . / \theta / \\
\text { (/t/ replaces the } \\
\text { sound } / \theta / \text { e.g. } \\
\text { in } \text { thing) }\end{array}$ & $\begin{array}{l}4 / v / \text { vs. /w/ } \\
\text { (/w/ replaces } \\
\text { /v/ in initial } \\
\text { position, e.g. } \\
\text { in visit) }\end{array}$ \\
\hline $\begin{array}{l}\text { First } \\
\text { interview }\end{array}$ & $19^{13}$ & $\begin{array}{l}\text { Accuracy rate } \\
40 \%\end{array}$ & $\begin{array}{l}\text { Accuracy rate } \\
21 \% \\
\text { (Accuracy rate } \\
\text { think } 25 \% \text { ) }\end{array}$ & Accuracy rate 0 \\
\hline $\begin{array}{l}\text { Second } \\
\text { interview }\end{array}$ & 2 & $\begin{array}{l}\text { Accuracy rate } \\
40 \%\end{array}$ & $\begin{array}{l}\text { Accuracy rate } \\
53 \% \\
\text { (Accuracy rate } \\
\text { think } 57 \% \text { ) }\end{array}$ & Accuracy rate 0 \\
\hline
\end{tabular}

\section{Fluency}

With regard to the first variable, fluency, it is striking how much the student's English has improved $^{14}$. In the first interview it is clear that the student is unable to produce everyday words such as beat (slå), subject (fag), power (kraft) and phrases such as or something like that (eller noe sånt). ${ }^{15}$ Instead of making an attempt to explain what she means by using other words, she simply translates the word into Norwegian: “...on Friday we slo, nei...”, "Ungdomsskolen was easy. I could get five or six in every fag”. "Where did she stay?"16 "Tampa eller noe sånt". The conversation uncovered that the student's vocabulary is limited and also that she lacks awareness about how to use fixed conventional phrases, "smallwords"

\footnotetext{
${ }^{12}$ Words such as really, I mean, oh. See Hasselgren (1998).

${ }^{13}$ Number of times where the student is unable to continue the conversation or resorts to a Norwegian word.

${ }^{14}$ See table 1.0 .

${ }^{15}$ Appendix 1.

${ }^{16}$ My question to the student.
} 
and fillers ${ }^{17}$. In fact, such words and phrases are virtually non-existent in this student's vocabulary.

In the second interview there is only one example of the student using a Norwegian word (klima) instead of the English climate, and these words are also very similar in the two languages, so it is not entirely clear to me whether she just pronounces the English word a bit sloppily. There is only one example of the student being unable to explain exactly what she intends to say. She talks about the mountains in an American state and says that they are "kinda new mountains 'cos they're really...I don't know how to..." The word she is searching for is probably pointed (spiss). Even though she has problems finding the exact word in this situation, she does not resort to speaking Norwegian and she uses English to express that she might need some help finding the correct word. This clearly shows that her communication skills in English have improved.

Furthermore, in the second interview the student uses fillers and "smallwords" as shown in the following examples:

"The first school, ok, it was in X, a really conservative state and it's kind of different compared to the rest of the United States, and eh...I don't know if I can like...”

"... and the first school was really strict and you actually had to learn something before you...yeah...went out to take a test and stuff... and on the other school it was kinda easier, but that school was more...I don't know...in my opinion laid back".

“...eh...not in the beginning of the year, that was a piece of cake, but eh...when you like change high school in the middle of the year, it's kinda hard'cos then like all the friend groups are already made... and stuff..."

According to Hasselgreen (1998), the use of "smallwords" helps to maintain the speech flow and indicates better fluency, another observation that supports the statement that the student has improved her speaking skills.

\section{Subject-verb agreement}

In this section I will discuss the student's use of subject-verb agreement. When listening to the first interview with the student, it is clear that she makes several mistakes in this area compared to what is the norm in Standard English, and there are also examples of the student showing doubt about which form to choose: "My sister is... are very often in the...”, “... and it's...have been difficult with school work...". There is also an example of omission of the auxiliary verb: “...in Egypt we swimming a lot”. Furthermore, there is one instance where the student chooses the incorrect verb-form after a plural form of the noun: “...yesterday we was

\footnotetext{
${ }^{17}$ Fillers are words used e.g. to create time to speak, such as kind of, you know, let me see etc. (Luoma (2004).
} 
with adults in the second division" ${ }^{\prime 18}$. This is a rare example, however, so I have chosen to investigate further subject-verb agreement with regard to third person, present tense, because the third person singular $-\mathrm{s}$ is claimed to be a difficult feature to acquire. I have not included the phrase "it's - it is" in the results, as this seems to be an automatized combination of words, at least among most Norwegian students, and one which this student masters perfectly.

In the first interview there are five cases of a third person subject being followed by a verb in present tense. Examples of lack of subject-agreement with regard to third person present tense are: “...she also have a brother..." and "...she have also a sister..." Examples of correct forms are: “...he drives a Porsche to school..." and "...a brother who is sixteen..." The student chooses the incorrect form three out of five times ${ }^{19}$, which gives an accuracy score of $40 \%$. This is actually similar to other studies of this grammatical feature ${ }^{20}$, but the current study is very limited and it is impossible to know if the student would have gained a similar result in a more extensive study, which, for instance, would have included more and longer interviews and topics that would have "forced" the student to use this feature more.

In the second interview it is evident that the student still makes mistakes with regard to subject-verb agreement. General examples of lack of subject-verb agreement are: “...kind of the cliques and the people was already made..." and "...in $\mathrm{X}^{21}$ it was ${ }^{22}$ not too many fat people..." Furthermore, there are several examples of mistakes with regard to s-v agreement third person, present tense: "Norwegian soccer is more a thinking game that have gone like more far" (Note that the first verb form used in the sentence "is" is correct). "Eh, yeah, he do". " $X^{23}$ have a really bad rumour". Some examples of correct forms being used are: “...where my uncle works...", “...who cares about the grades...”, "it depends on what school..."

In the second interview, there are 15 instances which require subject-verb agreement in third person, present tense, and the accuracy rate this time is, maybe surprisingly, $40 \%$, exactly the same as in the first interview. Again the hypothesis that this grammatical feature is difficult to acquire for L2 learners of English is supported, as it seems as if one year in an English-speaking environment has not led to significant improvement of this grammatical feature for this student. As mentioned in the theory section pp. 2-3, there might be a multitude

\footnotetext{
${ }^{18}$ For a discussion of similar examples of mistakes, see Wiland ch. 6.2 .3 p. 284.

${ }^{19}$ Indecisiveness (student including both the correct and the incorrect form) has been counted as an error.

${ }^{20}$ Accuracy rate 37.55 (Ellis et al 2009: 267).

${ }^{21}$ Place name mentioned.

${ }^{22}$ In this example the student does not master the distinction between "it" and "there", but this feature will not be discussed in this article.

${ }^{23}$ Name mentioned.
} 
of reasons why the student has not improved, such as lack of instruction, motivation and a variety of affective variables. However, the student has not been asked to provide information about whether she received form-focused language instruction or experienced for instance lack of motivation during her stay in the USA. Hence, further investigation is needed to explain her lack of improvement in the area of subject-verb agreement.

\section{$/ \mathbf{t} / \operatorname{versus} / \boldsymbol{\theta} /$}

When it comes to the replacement of the sound $/ \theta /$ by the sound $/ t /$, this occurs 15 times in the first interview and 6 times in the second interview. In the first interview $/ t /$ is used in words such as thirteen, both, three, south, Thursday, math and think. In the second interview the sound / $/$ / has replaced $/ \theta /$ in the following words: think, through, north and both. Only one of these words occurs in both interviews, think.

However, in the first interview the student pronounces the $/ \theta$ / sound correctly in the word thing, as well as pronouncing the $/ \theta /$ sound in the word think three out of 12 times (accuracy rate 25\%). All the other words mentioned in this section are only used once, so it is impossible to know whether the student occasionally pronounces these using a $/ \theta /$ sound. But at least the student has shown that she is aware (consciously or unconsciously) of the fact that the sound / $\theta$ / exists in English.

In the second interview the student replaces the $/ \theta /$ sound with $/ \mathrm{t} /$ four out of seven times in the word think (57\% accuracy rate compared to $25 \%$ in the first). Even though this study is very limited, the student seems to have improved in this area. The word through is pronounced with a $/ \mathrm{t} /$ sound all four times it is used, but as it was not used in the first interview a comparison cannot be made. North is used only once, pronounced with a / $\mathrm{t}$ / sound. Finally, the word both occurs twice in the second interview, and both the /t/ sound as well as the $/ \theta$ / sound is used.

In addition, the student pronounces the following words with a $/ \theta$ / sound: something, thought, thanks and seventeenth. As these words only occur one time each during the interview, it is impossible to say whether the student also occasionally pronounces them using the non-standard /t/ sound.

To conclude this section it seems clear that the student has improved with regard to the pronunciation of the unvoiced th sound. In the first interview there are 19 words that are pronounced with an unvoiced th sound in Standard English. The student pronounces four of 
these words using the standard $/ \theta$ / sound, which equals an accuracy rate of $21 \%$. In the second interview the $/ \theta /$ sound occurs in 9 out of 17 words, which provides an accuracy rate of $53 \%$ and accounts for a considerable rate of improvement. Nevertheless, it is also evident that even such a long period of time as one year in a native English-speaking environment does not necessarily ensure a native-like pronunciation of all sounds of the English language.

\section{$/ \mathbf{v} / \operatorname{versus} / \mathbf{w} /$}

As for the fourth variable v vs. $\mathrm{w}$ in initial position of a word, it is interesting to note that the student has retained her pronunciation of the $\mathrm{v}$-sound in the word visit. After having spent one year in the USA she still pronounces it "wisit". Before she went to the USA she pronounced the words very, vacation and volleyball with a clear v-sound. In the second interview these words are still pronounced correctly, as one would expect. It is difficult to explain why it seems to be more difficult for this student to pronounce the word visit correctly than vacation and very, as they are all relatively prevalent words in English.

The results above in section 3 and 4 support the hypothesis that phonology is a particularly difficult area for L2 learners of a language. For most non-native speakers it is impossible to sound like native speakers, even after a relatively long period of exposure to the target language ${ }^{24}$. This study also supports these findings, and when a native speaker was asked to assess the student in the two interviews in terms of native-like pronunciation, she actually thought that they sounded very similar to each other. Bear in mind that she thought that she was listening to two different students, and she did not know anything about their age, background etc. My anticipation was that she would judge the person in the second interview to sound much more native-like than the person in the first interview, but in her opinion the student in the second interview sounded just slightly more like a native speaker than the person in the first interview in terms of phonology. However, the native speaker did comment upon the fact that the second speaker had a better vocabulary and expressed herself more fluently.

\section{Conclusion and didactic implications}

\footnotetext{
${ }^{24}$ See e.g. Ortega (2009).
} 
My conclusion is that this student's ability to express herself fluently in oral English has improved noticeably after having spent one year in an English-speaking environment. She has improved her vocabulary, developed her communication skills and learned how to compensate for lack of specific vocabulary. There are still several mistakes with regard to subject-verb agreement, a part of the English grammar that seems particularly difficult to master. As for phonetics, the student has improved her pronunciation of the unvoiced th sound considerably, whereas the v-sound which is less prevalent in English is still pronounced /w/ in the word visit. Interestingly, the student pronounces the two words very and vacation with a $/ \mathrm{v} /$ sound in both interviews.

Thus, the results of this study support the theories presented earlier in this article and the hypothesis that some language features may be more difficult to acquire than others. The student has improved her vocabulary considerably, and there is also improvement with regard to the pronunciation of the $/ \theta /$ sound. As for the accuracy rate for the $/ \mathrm{v} /$ sound in visit and third person $-\mathrm{s}$, present tense, the results may be interpreted as fossilization. It is important to note, however, that as this is a very limited study, the results must be treated with caution. It would have been interesting to study the development of oral English skills among a larger number of exchange students, preferably of mixed abilities, to achieve more reliable and valid research results.

Taking the results of this case study into account it seems clear that there are some aspects of the English grammar and phonology that are more difficult to improve than others once a student is past a certain age. Consequently, I think English teachers in Norwegian primary schools should focus more on phonetics and intonation, as students in primary school are at an age where they are more perceptive to phonetic variation. The students should listen to and practice the different sounds of English, in addition to developing their vocabulary and using English to speak and write freely. However, in order to achieve improved oral skills among young learners, it is necessary to employ competent English teachers in lower secondary school.

English teachers in secondary school should, in my opinion, to a greater extent focus on encouraging the students to read different kinds of literature in English, developing reading strategies and expanding students' vocabulary ${ }^{25}$. Extensive reading improves students' vocabulary and may also help to automate grammatical features. In addition, it may help

\footnotetext{
${ }^{25}$ Vocabulary knowledge is highly correlated with reading comprehension (Long and Doughty p. 443, 445).
} 
students improve their grammar to receive form-focused instruction on certain grammatical features ${ }^{26}$.

As for English teachers in upper secondary school they should work more systematically to improve students' vocabulary ${ }^{27}$. Obviously, not all students can be sent abroad to improve their language skills. Still, teachers should focus more not only on everyday vocabulary, but also work with vocabulary for specific purposes, including preparing students for higher education. In addition, students need to learn effective communication skills that may compensate to a certain extent for lack of appropriate vocabulary. With regard to pronunciation, it seems to be difficult to change the pronunciation of certain sounds after a certain age. However, it might help some students to improve if they are individually made aware of how sounds are produced and pronounced.

When it comes to grammar instruction in upper secondary school I still think it is important to focus on grammar in students' written work. Being able to write e.g. a CV and an application in good English is a valuable skill. However, in some cases spending hours teaching and correcting s-v agreement may be a waste of students' as well as the teacher's time. Highly motivated and apt students will eventually master this grammatical feature once they have understood the rules, whereas less motivated students often never will.

To conclude, lack of subject-verb agreement and replacing / $\theta /$ with $/ \mathrm{t} /$ seldom creates communication problems in oral communication situations. A limited vocabulary and poor communications skills, however, do hinder communication. Consequently, my cautious statement would be that the aim of language teachers in upper secondary school should be to improve their students' vocabulary and ability to communicate fluently in a multitude of oral communication situations.

\section{References}

Askland, S. (2010). The Role of instruction and Corrective Feedback in Second Language Acquisition, master's thesis, University of Agder

Bygate, M. (2011). Teaching and Testing Speaking. In Long and Doughty (ed.). (2011). The Handbook of Language Teaching. Wiley-Blackwell

\footnotetext{
${ }^{26}$ Lightbown and Spada (2006), Ortega (2009: 139).

${ }^{27}$ Researchers claim that vocabulary can be taught at any time (Lighbown and Spada 2006: 160).
} 
Ellis, R., Loewen, S., Elder, C. Erlam, R., Philp, J., \& Reinders, H. (2009). Implicit and Explicit Knowledge in Second Language Learning, Testing and Teaching. Multilingual Matters

Hasselgreen, A. (1998). Smallwords and valid testing. (Doctoral dissertation, the University of Bergen, 1998).

Krashen, S. D. (1982). Principles and Practice in Second Language Acquisition, Pergamon Press

Lightbown, P. M. and N. Spada (2006). How languages are learned. Oxford, Oxford University Press.

Luoma, S. (2004). Assessing Speaking. Cambridge University Press

McLaughlin, B. (1984). Language Learning in Childhood and Adulthood. Hillsdale NJ: Erlbaum

Ortega, L. (2009). Understanding Second Language Acquisition, Hodder Education London

Ringbom, H and Jarvis, S (2011). The Importance of Cross-Linguistic Similarity in Foreign Language Learning. In Long and Doughty (ed.). (2011). The Handbook of Language Teaching. Wiley-Blackwell

Selinker, Larry (1972). Interlanguage. IRAL, Vol. X/3, 1972, Julius Groos Verlag, Heidelberg In Richards, J. K. (1974). Error Analysis Perspectives on Second Language Acquisition, Longman

Singleton, D.M. (1989). Language Acquisition. The Age Factor. Clevedon: Multilingual Matters Ltd.

Wiland, S. M. (2007). Poetry: Prima Vista Reader-Response Research in a Foreign Language Context. (Doctoral dissertation, the University of Bergen, 2007)

\section{APPENDIX 1 \\ Overview of student's errors}

First interview 


\section{Fluency}

Norwegian words used to replace English words the student doesn't know:

stall, langrenn, kraft, serie, slå, ambassade, forsikring, fag, om gangen, rettslære, hos, «... eller noe sånt...», «... også husker jeg ikke flere...»

\section{Subject-verb agreement}

my sister are, we was, we swimming, it have been, she start, she have

\section{/ $\boldsymbol{\theta} /$ versus $/ \mathbf{t} /$}

thirteen, both, south, think (used 9 times), three, math, Thursday ${ }^{28}$

$/ \mathbf{v} /$ versus /w/

4: visit $>$ wisit

\section{Second interview}

\section{Fluency}

klima, searches for the word "spiss" in English when referring to mountains

\section{Subject-verb agreement}

family come first, she like, he do, $X^{29}$ have..., the crap that have happened, the cliques and the people was...

/ $\boldsymbol{\theta} /$ versus $/ \mathbf{t} /$

north, through ( 3 times), think ( 2 times), both (2 times)

$/ \mathbf{v} /$ versus /w/

visit $>$ wisit

\footnotetext{
${ }^{28}$ Words that the student pronounces incorrectly.

${ }^{29}$ Name mentioned.
} 